\title{
Avaliação da fragmentação da cobertura arbórea de Maringá/PR utilizando geotecnologias
}

Tree canopy cover fragmentation analysis in Maringá/PR using geotechnologies

\author{
F. H. Mendes*; F. C. S. Petean; J. L. Polizel; D. F. Silva Filho \\ Departamento de Ciências Florestais / Laboratório de Métodos Quantitativos / Setor de Arborização Urbana, Escola \\ Superior de Agricultura "Luiz de Queiroz", Universidade de São Paulo, CEP: 13.418-900, Piracicaba-São Paulo, \\ Brasil \\ *friquemendes@usp.br \\ (Recebido em 29 de fevereiro de 2016; aceito em 12 de agosto de 2016)
}

\begin{abstract}
A cobertura arbórea urbana desempenha um papel fundamental na manutenção do equilíbrio ambiental nas cidades. O uso de recursos e ferramentas gratuitas, que auxiliem os tomadores de decisão no planejamento e manejo das florestas urbanas, é uma tendência que deve ser incentivada. O objetivo deste trabalho foi avaliar a fragmentação e conectividade da cobertura arbórea urbana da cidade de Maringá/PR, por meio da aplicação do complemento LecoS de ecologia de paisagem, utilizando como base imagens e programas gratuitos. Para a extração das classes de uso e ocupação do solo, imagens RapidEye dos anos de 2012 e 2013 foram recortadas tomando como base a mancha urbana do município, e, em seguida, submetidas à classificação supervisionada. No programa livre Quantum GIS, aplicou-se a função Effective Mesh Size (meff) do complemento de ecologia de paisagens LecoS, a fim de obter as porcentagens de fragmentação da cobertura arbórea com base na área total da classe. Observou-se que a cobertura arbórea urbana de Maringá reduziu $11,4 \%$ entre 2012 e 2013 (de 14,9\% para 13,2\%), muito provavelmente devido ao manejo da vegetação (supressão). No entanto, a conectividade entre os fragmentos aumentou de $0,4 \%$ para $16,8 \%$ no mesmo período, indicando que lacunas na cobertura arbórea estão se fechando, tornando-a mais homogeneamente distribuída. Demais variações encontradas nas imagens são devidas à qualidade e à resolução espacial. É desejável que a cobertura arbórea esteja distribuída igualmente no tecido urbano, para que um número maior de habitantes desfrute dos benefícios trazidos pelas árvores às cidades.

Palavras-chave: arborização urbana, conectividade, ecologia da paisagem
\end{abstract}

Urban tree cover plays a key role in maintaining the environmental balance in cities. Using free tools and resources help decision makers in the planning and management of urban forests, is a trend that should be encouraged. The objective of this study was to evaluate the fragmentation and connectivity of urban tree cover of Maringa, Brazil, through the application of LecoS complement of landscape ecology, using free images and programs. For the extraction of land use/land cover classes, RapidEye images from 2012 and 2013 were cut based on the municipality urban area, and, then, submitted to supervised classification. In Quantum GIS, the function Effective Mesh Size (meff) of LecoS landscape ecology complement was applied in order to get the fragmentation percentages of tree cover. It was observed that Maringa's urban tree canopy cover reduced $11.4 \%$ between 2012 and 2013 (from $14.9 \%$ to 13.2\%), most likely due to vegetation management (supression). However, connectivity between fragments increased from $0.4 \%$ to $16.8 \%$ in the same period, indicating that gaps in tree cover are closing, making it more evenly distributed. Other variations found in the images are due to the quality and spatial resolution. It is desirable that tree cover is equally distributed in the urban tissue, so that more people will enjoy the benefits brought by trees to the cities.

Keywords: urban forest, connectivity, landscape ecology

\section{INTRODUÇÃO}

O território está sob constante transformação. A todo o momento áreas de floresta são abertas para dar espaço a pastagens. Estas, por sua vez, são convertidas em campos agrícolas e, por fim, campos agrícolas abrem caminho para a expansão das cidades. Este fenômeno exemplifica o modelo de ocupação do território no Brasil. Enquanto a crescente necessidade de expansão das fronteiras agrícolas promove mudanças no campo, a dinâmica populacional estimula a expansão dos limites urbanos. 
Independentemente do contexto, o fator de transformação é o homem. Suas atividades alteram a dinâmica dos elementos que compõem a paisagem, como, por exemplo, a interrupção do fluxo gênico entre populações de mamíferos, causada pela construção de uma rodovia ou pela abertura de um campo agrícola. A consequência quase sempre é a fragmentação de hábitat. Embora estes sejam exemplos tangíveis, o homem é incapaz de assimilar o real efeito dessas interferências na estrutura da paisagem. É preciso o emprego de uma visão holística para compreender o papel ou efeito que uma mudança pontual pode causar na paisagem como um todo [1,2].

Quando o objeto de estudo são as áreas naturais, ou seja, áreas pouco antropizadas que desempenham papéis ecológicos para o equilíbrio do ecossistema, o entendimento de como o estabelecimento de barreiras físicas ou a fragmentação de áreas florestadas podem interferir na dinâmica da paisagem, é imprescindível para evitar a perda da funcionalidade dessas mesmas áreas no contexto geral. Para tanto, são analisadas diversas métricas da paisagem para avaliar de que forma a dinâmica está sendo afetada pelas atividades humanas. A quantificação, modelagem e interpretação desses parâmetros servem como base para a elaboração de leis de uso e ocupação do solo tais como a Lei de Ordenamento Territorial, cuja função primordial é nortear o modo pelo qual o solo está sendo modificado e seu impacto na paisagem. Por outro lado, as cidades são excelentes laboratórios que nos permitem vivenciar claramente a dinâmica dos elementos da paisagem nos mais diversos níveis de interação, devido a suas constantes alterações. As mudanças no cenário são mais facilmente percebidas devido ao grau de intimidade do cidadão com o ambiente que o cerca. Assim, ao menor sinal de alteração, a pessoa se sente mais afetada, seja positiva ou negativamente.

Diversas ferramentas foram desenvolvidas em ambiente SIG para auxiliar na obtenção das métricas de paisagem [2]. Programas foram elaborados exclusivamente para computar métricas de ecologia de paisagem e estão cada dia mais acessíveis aos tomadores de decisão de forma gratuita, como o complemento para o programa livre Quantum Gis, LecoS. O LecoS (ou Landscape Ecology Statistics) foi desenvolvido para computar diversos parâmetros básicos e avançados para estudos em ecologia de paisagens [3]. Nele é possível acessar funções que avaliam o grau de fragmentação e de conectividade da paisagem, tal como o Effective Mesh Size (meff). Segundo Jaeger (2000) [4], a função meff indica a possibilidade de que dois pontos escolhidos aleatoriamente na paisagem se conectem. Portanto, quanto mais barreiras houver na paisagem, tais como rodovias, linhas de alta tensão, campos agrícolas, etc., menor será a probabilidade de conexão e, desse modo, menor será o meff, como visto em trabalhos sobre fragmentação de hábitats [5, 6]. Sua aplicação em estudos florestais é crescente, como visto nos trabalhos de Girvetz et al. (2008) [7], Jaeger et al. (2008) [8], Gao \& Li (2011) [9], Freitas et al. (2012) [10], Marull et al. (2014) [11] e Su et al. (2014) [12].

O uso combinado de ferramentas gratuitas com recursos de alta resolução, como imagens de satélite, possibilita a obtenção mais precisa de dados e informações. Recentemente, o Governo Federal, por meio do Ministério do Meio Ambiente, disponibilizou de forma gratuita imagens de todo o país do sensor orbital RapidEye obtidas entre os anos de 2011 e 2013. O sensor tem resolução espacial de $5 \mathrm{~m}$ e fornece imagens com cinco bandas espectrais: azul $(440-510 \mathrm{~nm})$, verde $(520-590 \mathrm{~nm})$, vermelha $(630-685 \mathrm{~nm})$, red edge $(690-730 \mathrm{~nm})$ e infravermelho próximo (NIR) (760-850 nm) [13] que, quando colocada no canal do vermelho, realça a vegetação facilitando a identificação de áreas florestadas. A partir de imagens de satélite, tais como as do RapidEye, é possível avaliar mudanças temporais no uso e ocupação do solo, como o aumento ou diminuição da cobertura arbórea urbana.

A cobertura arbórea inserida no tecido urbano desempenha um papel importantíssimo, atuando como mitigadora dos efeitos das ilhas de calor, como sumidouro de gases do efeito estufa tal qual o $\mathrm{CO}_{2}$, como abrigo da fauna nativa local, como atenuante de doenças psicológicas e do estresse, entre outros tantos benefícios. Avaliar a maneira com qual a cobertura arbórea urbana se modifica ao longo dos anos é essencial para o manejo e o planejamento de ações de arborização. Em um cenário ideal, a cobertura arbórea deve ser bem distribuída ao longo do tecido urbano. Assim, torna-se possível a conexão entre áreas verdes urbanas, como parques e praças, com fragmentos florestais e áreas de proteção permanente, como margens de rios. Vias urbanas arborizadas atuam como corredores verdes, permitindo o fluxo de fauna entre as áreas verdes, promovendo, dessa forma, a biodiversidade e o equilíbrio do ecossistema local. 
O objetivo da pesquisa foi avaliar a conectividade e fragmentação da cobertura arbórea urbana da cidade de Maringá/PR, entre os anos de 2012 e 2013, por meio de classificação supervisionada e análise de parâmetros de ecologia de paisagens.

\section{MATERIAL E MÉTODOS}

\section{1 Área de estudo}

A cidade de Maringá (Figura 1) se encontra na região centro-norte do Estado do Paraná, nas coordenadas $23^{\circ} 25^{\prime}$ sul e $51^{\circ} 56^{\prime}$ oeste. O relevo da região é suave a ondulado, variando entre 500 e 600 m acima do nível do mar e os tipos de solo predominantes são: Nitossolo, Latossolo Roxo, Latossolo Vermelho-Escuro e Neossolo Litólico [14]. O município possui uma extensão territorial de $487,930 \mathrm{~km}^{2}$, com taxa de urbanização de $98 \%$ e densidade populacional de aproximadamente 803 hab. $\mathrm{km}^{-2}$, sendo $27 \%$ do território em área urbano e $73 \%$ em área rural [15]. Conforme censo de 2014 do IBGE, Maringá possui 391.698 habitantes.

O clima, segundo a classificação de Köppen, é do tipo Cfa (subtropical), com pluviosidade média anual de $1500 \mathrm{~mm}$, pertencente ao domínio da Floresta Estacional Semidecidual [16]. A Floresta Estacional Semidecidual é uma formação pertencente ao bioma Mata Atlântica que cobria originalmente $84,7 \%$ da área do Estado do Paraná. Em pouco mais de 100 anos, com a exploração da madeira - especialmente a madeira da Araucária (Araucaria angustifolia (Bertol.) Kuntze) ou Pinheiro do Paraná -, a abertura de estradas de ferro, de áreas agrícolas e o avanço da colonização para o oeste do Estado, as florestas nativas se reduziram a aproximadamente $10 \%$ da cobertura original $[17,15]$.

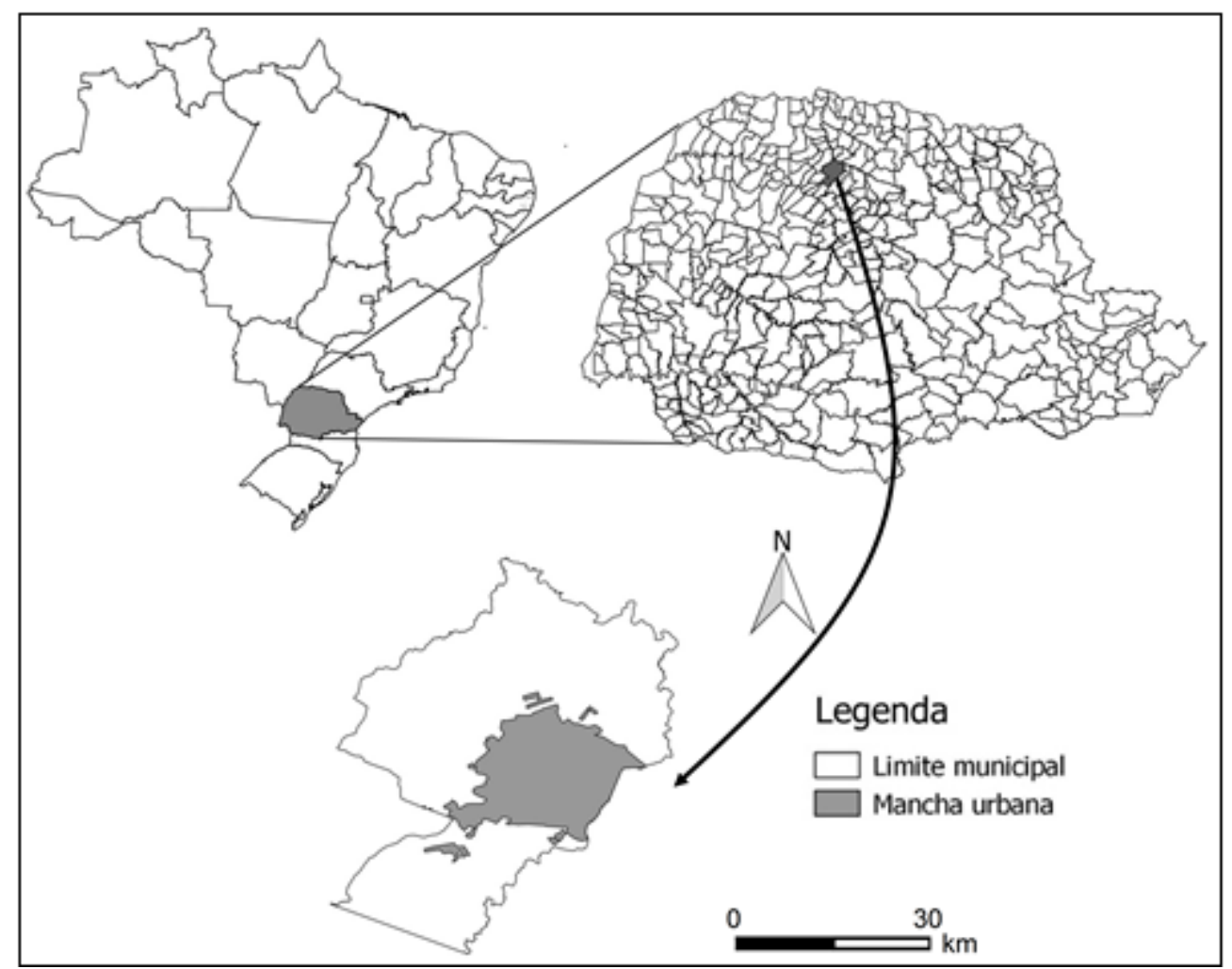

Figura 1: Localização geográfica do município de Maringá, situada na região centro-norte do Estado do Paraná, Brasil. Em destaque, o limite municipal e a mancha urbana 


\subsection{Base de dados digitais}

Obteve-se por meio do Geo Catálogo (2015) [18] - base de dados digital de imagens de todo o país geradas pelo sensor orbital RapidEye -, pertencente ao Ministério do Meio Ambiente, imagens de 2012 e 2013, datadas de 11 de novembro e 16 de agosto, respectivamente, de Maringá/PR, georreferenciadas em UTM / WGS 84 zona 22 S. Cada imagem era composta por 4 cenas, sendo necessário realizar um procedimento de "mosaicagem", isto é, a fusão digital de cenas complementares que cobrem uma área de interesse, em uma única imagem, em ambiente SIG; para isso, utilizou-se o programa livre Quantum GIS versão 2.6 Brighton. Para extrair a mancha urbana da área rural, utilizou-se um arquivo vetorial do tipo shapefile da mancha urbana da cidade e, por meio da ferramenta camada máscara, fez-se o recorte da área de interesse.

\subsection{Classificação supervisionada}

A quantificação da cobertura arbórea foi feita pelo método da classificação supervisionada. Para tanto, foi utilizado o programa gratuito MultiSpec versão 3.4. A composição das bandas em ambas as imagens foi RGB 5/2/1, com o objetivo de realçar a vegetação (Figura 2).

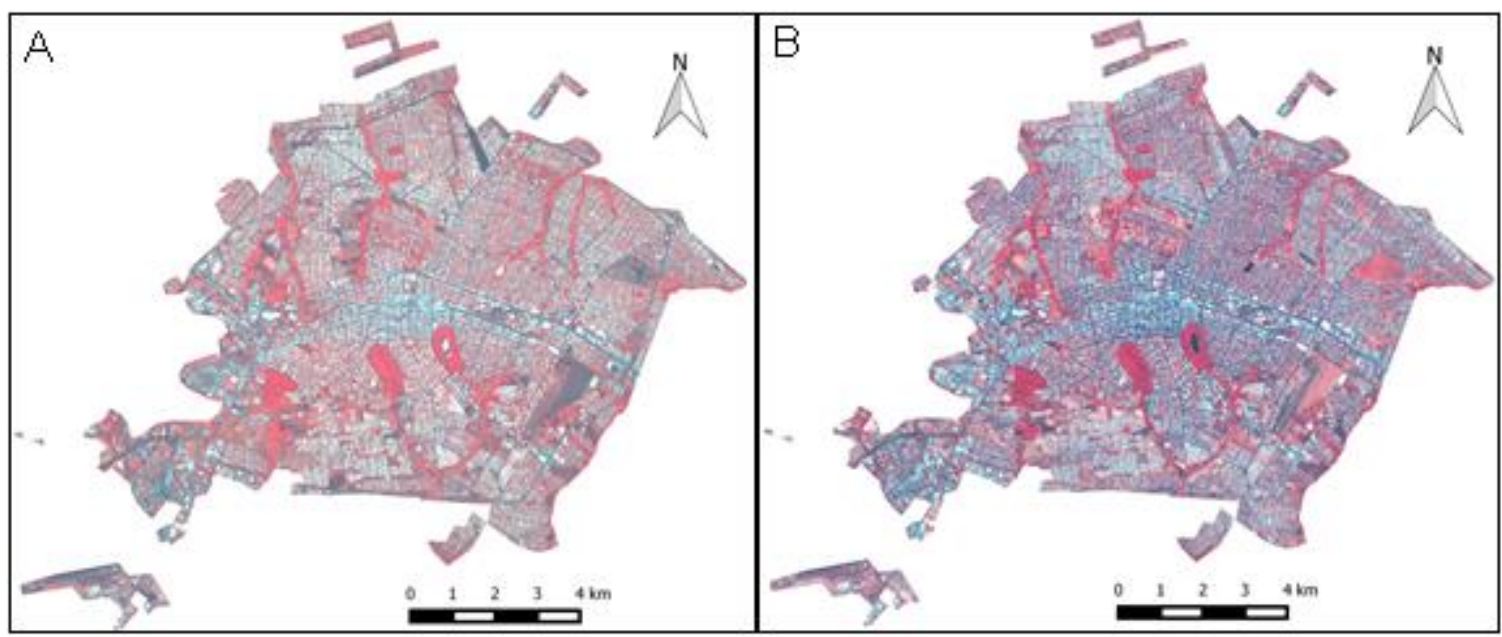

Figura 2: Imagens RGB 5/2/1 da mancha urbana de Maringá, Paraná: (A) - Imagem datada de novembro de 2012; nota-se uma imagem com excesso de claridade devido a um índice de reflectância maior, causado pela incidência solar da época em que foi adquirida. (B) - Imagem datada de outubro de 2013; não se nota interferência por excesso de claridade

Foram estabelecidas oito classes de uso e ocupação de solo: copa de árvore, relvado, solo exposto, asfalto, sombra, rio/lago, telhados e fundo da imagem, sendo que esta última foi posteriormente excluída para que não interferisse no cômputo das porcentagens das classes na imagem. Destaca-se que não foi possível decompor os telhados em mais classes em virtude da baixa resolução espacial (tamanho de pixel de $5 \mathrm{~m}$ ), que dificulta o maior detalhamento e lançamento de amostras. Para cada classe foram determinadas 20 amostras de treinamento e teste, com exceção à "copa de árvore" onde se determinou o dobro de amostras por ser esta a classe de interesse.

A fim de determinar o melhor classificador (algoritmo) para a classificação supervisionada, foram testados todos os classificadores disponíveis no programa MultiSpec na imagem de 2012. Ao analisar o índice Kappa (K), nota-se que o algoritmo ECHO (Extraction and Classification of Homogeneous Objects) se destaca $(\mathrm{K}=93,8 \%)$, seguido pelo Maximum Likelihood (K =93,7\%) e Minimum Euclidean Distance $(\mathrm{K}=90,7 \%)$, conforme Tabela 1. 
Tabela 1: Comparação da performance dos classificadores segundo o índice Kappa (K). Nota-se que o algoritmo ECHO obteve desempenho maior na classificação de um modo geral, seguido pelo Maximum Likelihood e Minimum Euclidean Distance.

\begin{tabular}{|c|c|c|c|c|c|c|c|}
\hline Classe & ECHO & $\begin{array}{l}\text { Maximum } \\
\text { Likelihood }\end{array}$ & $\begin{array}{c}\text { Minimum } \\
\text { Euclidean } \\
\text { Distance }\end{array}$ & $\begin{array}{c}\text { Fisher } \\
\text { Linear } \\
\text { Likelihood }\end{array}$ & $\begin{array}{c}\text { Parallel } \\
\text { Piped }\end{array}$ & $\begin{array}{c}\text { Correlation } \\
\text { (SAM) }\end{array}$ & $\begin{array}{c}\text { Matched } \\
\text { Filter } \\
\text { (CEM) }\end{array}$ \\
\hline Copa de árvore & $14,9 \%$ & $14,9 \%$ & $23,8 \%$ & $25,0 \%$ & $6,0 \%$ & $66,3 \%$ & $71,9 \%$ \\
\hline Relvado & $16,0 \%$ & $16,0 \%$ & $2,2 \%$ & $0,9 \%$ & $4,4 \%$ & $5,7 \%$ & $1,1 \%$ \\
\hline Solo exposto & $15,5 \%$ & $17,5 \%$ & $35,6 \%$ & $46,0 \%$ & $57,1 \%$ & $21,0 \%$ & $15,8 \%$ \\
\hline Asfalto & $4,1 \%$ & $4,8 \%$ & $32,0 \%$ & $15,5 \%$ & $1,4 \%$ & $4,9 \%$ & $9,2 \%$ \\
\hline Sombra & $5,9 \%$ & $6,6 \%$ & $1,8 \%$ & $6,3 \%$ & $0,7 \%$ & $0,3 \%$ & $0,4 \%$ \\
\hline Rio/lago & $0,0 \%$ & $0,0 \%$ & $0,0 \%$ & $2,0 \%$ & $0,0 \%$ & $0,0 \%$ & $0,3 \%$ \\
\hline Telhados & $43,5 \%$ & $40,1 \%$ & $4,6 \%$ & $4,2 \%$ & $30,4 \%$ & $1,8 \%$ & $1,4 \%$ \\
\hline Kappa & $93,8 \%$ & $93,7 \%$ & $90,7 \%$ & $88,2 \%$ & $84,9 \%$ & $18,9 \%$ & $13,4 \%$ \\
\hline
\end{tabular}

Dessa forma, o algoritmo ECHO foi utilizado para a execução da classificação supervisionada da imagem de 2013.

\subsection{Análise da ecologia da paisagem}

Uma vez escolhido o algoritmo e executada a classificação para ambas as imagens, foi aplicado complemento de estatísticas de ecologia de paisagem LecoS (Landscape Ecology Statistics), disponível gratuitamente para o programa livre Quantum GIS. Para verificar quão conectada ou fragmentada está a cobertura arbórea inserida no tecido urbano, foi analisada a estatística Effective Mesh Size (meff). No complemento foi preciso identificar a classe de fundo da imagem e o tamanho da célula. Em ambas as imagens, a classe 8 foi o fundo e o tamanho de célula igual a $25 \mathrm{~m}^{2}$, ou seja, $5 \mathrm{~m} \times 5 \mathrm{~m}$.

\subsection{Forma de análise dos dados}

Na classificação supervisionada foram analisados os índices K gerados a partir de matrizes de erro. O índice $\mathrm{K}$ representa o grau de concordância entre os valores obtidos e esperados. De acordo com Landis e Koch (1977) [19], os valores de K podem ser interpretados seguindo uma escala onde: $\mathrm{K}<0,00$, concordância pobre; $0,00<\mathrm{K}>0,20$, ligeira concordância; $0,21<\mathrm{K}>0,40$, concordância considerável; $0,41<\mathrm{K}>0,60$, concordância moderada; $0,61<\mathrm{K}>0,81$, concordância substancial; e $0,81<\mathrm{K}>1,00$, concordância excelente. A classificação que não alcançasse o mínimo de $80 \%$ de índice $\mathrm{K}$ geral foi refeita.

Para analisar os resultados do LecoS, observou-se os valores do meff, em porcentagem, em relação à área total da classe. As variações foram discutidas de acordo com a literatura.

\section{RESULTADOS E DISCUSSÃO}

As florestas urbanas desempenham um papel chave para a manutenção do bem estar dos cidadãos e para o equilíbrio do ecossistema local. Elas têm capacidade de imobilizar o $\mathrm{CO}_{2}$ atmosférico, diminuir os efeitos das enxurradas e permeabilizar o solo. Desse modo, avaliar o grau de fragmentação e conectividade das florestas urbanas é imprescindível para conhecer sua distribuição e planejar ações de manejo e plantio.

\subsection{Classificação supervisionada}

A figura 3 mostra os mapas temáticos da classificação supervisionada realizada pelo programa MultiSpec, para os anos de 2012 e 2013, utilizando o algoritmo ECHO. 


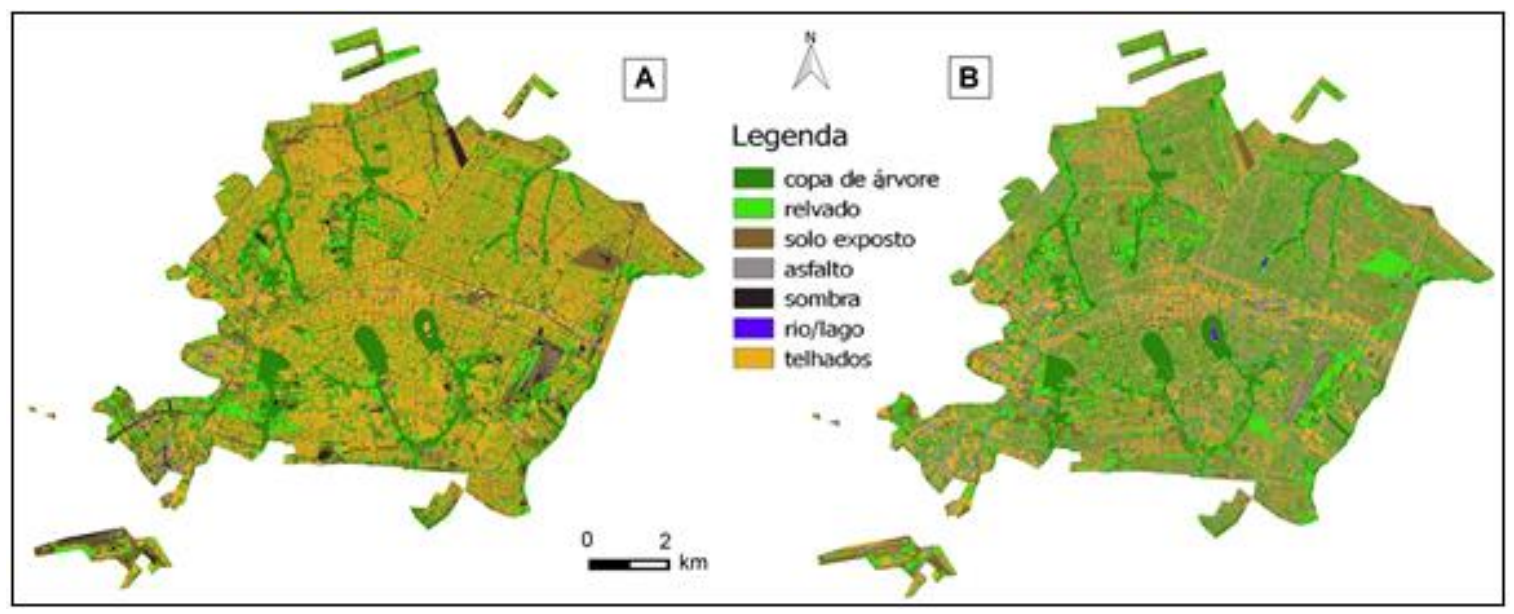

Figura 3: Classificação supervisionada da imagem RapidEye de Maringá, de 2012 (A) e 2013 (B), com a distinção de sete classes de uso e ocupação de solo, cujo índice K foi de 93,8\% e 96,7\%, respectivamente

Conforme observado na figura $2 \mathrm{~A}$, houve um excesso de claridade causado pela maior exposição solar na imagem, de cujo efeito prejudicou a classificação de algumas classes de uso de solo, como telhados e rio/lago. Na figura 3A, nota-se uma maior presença da classe "telhado" em detrimento das outras, enquanto que na imagem 3B, a melhor qualidade da imagem refletiu em uma melhor distribuição das classes. A classificação da imagem de 2013, ao contrário, não apresentou problemas de reflectância no momento da captura. $\mathrm{O}$ índice $\mathrm{K}$ obtido foi igual a 96,7\% que, segundo Landis e Koch (1977) [19], é considerada excelente.

A tabela 2 mostra a variação do uso e ocupação de solo entre os anos estudados. Os valores foram calculados com base na área da mancha urbana da cidade.

Tabela 2: Quantificação das classes de uso e ocupação de solo descritos para Maringá/PR. Os valores foram calculados tomando como referência a totalidade da área urbana do município

\begin{tabular}{lcc}
\hline \multirow{2}{*}{ Classe } & \multicolumn{2}{c}{ Uso e Ocupação do Solo } \\
\cline { 2 - 3 } & 2012 & 2013 \\
\hline Copa de árvore & $14,9 \%$ & $13,2 \%$ \\
Relvado & $16,0 \%$ & $24,2 \%$ \\
Solo exposto & $15,5 \%$ & $20,0 \%$ \\
Asfalto & $4,1 \%$ & $22,0 \%$ \\
Sombra & $5,9 \%$ & $0,8 \%$ \\
Rio/lago & $0,0 \%$ & $0,1 \%$ \\
Telhados & $43,5 \%$ & $19,7 \%$ \\
\hline Total & $100,0 \%$ & $100,0 \%$ \\
\hline
\end{tabular}

As diferenças entre as porcentagens do uso e ocupação de solo, encontradas pela classificação supervisionada das imagens estudadas, se devem, principalmente, ao horário, iluminação (incidência e inclinação solar), questões atmosféricas e época do ano em que foram capturadas. É por esse motivo que há variações mais acentuadas nas classes "Sombra" e "Asfalto". O excesso de reflectância da imagem de 2012 pode ter impedido que o programa interpretasse corretamente os pixels amostrados para a classe "Asfalto", subestimando seu valor real. Na classe "Sombra", houve o efeito da inclinação do sol devido a diferenças no horário de captura. Dessa forma, quanto mais próximo do horizonte, maiores serão as sombras projetadas e, portanto maiores serão os valores encontrados na classificação supervisionada.

Quanto à classe "Telhados", a variação verificada do ano de 2012 para 2013 foi devida aos índices de reflectância distintos das imagens. Como mencionado anteriormente, a imagem de 2012 apresentou um maior índice de reflectância em função da época em que foi capturada. Imagens capturadas próximas à época do verão, como foi o caso, recebem maior fluxo de radiação eletromagnética e tendem a se distorcer, dificultando a identificação das feições de 
interesse e a definição de classes. Desse modo, houve uma sobre estimação dos valores quando comparada a imagem de 2013.

Em relação às classes "Copa de árvore", "Relvado" e "Solo exposto", as variações encontradas são explicadas exclusivamente pelo manejo das áreas. A banda do infravermelho utilizada para ressaltar a vegetação sofre baixa influência dos efeitos atmosféricos, o que resulta em valores estáveis na classificação supervisionada, cujas variações se devem somente à natureza das feições, ou, no caso, do manejo dessas feições.

Os fenômenos atmosféricos são capazes de interferir na identificação das feições e no processamento das imagens. Nas etapas de pré-processamento, o viés atmosférico é comumente corrigido pela aplicação de filtros que eliminem ou atenuem as interferências. No entanto, um efeito colateral da aplicação de filtros é a perda de contraste e nitidez que, por sua vez, dificultam a correta alocação de amostras na classificação supervisionada. Neste trabalho, optou-se por não aplicar filtros que corrigissem o efeito de excesso de reflectância presente na imagem de 2012 para que a alocação das amostras não fosse prejudicada, aumentando o erro do usuário.

\subsection{Complemento LecoS}

As tabelas seguintes (Tabela 3 e 4) descrevem os resultados do uso da função meff em relação as classes de uso e ocupação do solo.

Tabela 3: Valores de Uso e Ocupação de Solo (UOS) das classes estudadas e da função Effective Mesh Size (meff) do complemento LecoS, para a imagem de 2012. Os valores de meff refletem a conectividade entre as classes

\begin{tabular}{lcccc}
\hline Classe & UOS & UOS \% & meff & meff \% \\
\hline Copa de árvore & 376216250 & $14,9 \%$ & 719714,1 & $0,4 \%$ \\
Relvado & 402331875 & $16,0 \%$ & 80118,3 & $0,0 \%$ \\
Solo exposto & 391890625 & $15,5 \%$ & 248515,6 & $0,1 \%$ \\
Asfalto & 104161250 & $4,1 \%$ & 14968,6 & $0,0 \%$ \\
Sombra & 149922500 & $5,9 \%$ & 23910,3 & $0,0 \%$ \\
Rio/lago & 388750 & $0,0 \%$ & 11,3 & $0,0 \%$ \\
Telhados & 1096046875 & $43,5 \%$ & 185075459,6 & $99,4 \%$ \\
\hline Total & 2520958125 & $100,0 \%$ & 186162697,7 & $100,0 \%$ \\
\hline
\end{tabular}

Tabela 4: Valores de Uso e Ocupação de Solo (UOS) das classes estudadas e da função Effective Mesh Size (meff) do complemento LecoS, para a imagem de 2013. Os valores de meff refletem a conectividade entre as classes

\begin{tabular}{lcccc}
\hline Classe & UOS & UOS \% & meff & meff \% \\
\hline Copa de árvore & 333244375 & $13,2 \%$ & 482742,7 & $16,8 \%$ \\
Relvado & 611268125 & $24,2 \%$ & 434248,2 & $15,1 \%$ \\
Solo exposto & 503657500 & $20,0 \%$ & 125723,3 & $4,4 \%$ \\
Asfalto & 554326875 & $22,0 \%$ & 1773403,6 & $61,6 \%$ \\
Sombra & 20108125 & $0,8 \%$ & 90,8 & $0,0 \%$ \\
Rio/lago & 1511250 & $0,1 \%$ & 467,6 & $0,0 \%$ \\
Telhados & 496669375 & $19,7 \%$ & 63034,7 & $2,2 \%$ \\
\hline Total & 2520785625 & $100,0 \%$ & 2879711,0 & $100,0 \%$ \\
\hline
\end{tabular}

Foi possível verificar que de 2012 para 2013 a cobertura arbórea reduziu 11,4\%, ou seja, de $14,9 \%$ para $13,2 \%$. Isto se deve às diferenças na qualidade da imagem, como dito anteriormente, e devido ao manejo da vegetação em si. Comparando os resultados obtidos com a literatura, notase que as porcentagens obtidas se aproximam daquelas descritas por Sampaio et al. (2012) [20]. Os autores encontraram valores de $14,1 \%$ no ano de 2012 trabalhando com imagens Landsat 5, 
cuja resolução espacial mínima é de $30 \mathrm{~m}$. A diferença entre as porcentagens destes autores e este estudo pode ser explicada devido à resolução espacial. $\mathrm{O}$ emprego de sensores orbitais de maior resolução espacial implica na melhor identificação e quantificação das feições de interesse, como por exemplo, as copas das árvores em ambiente urbano.

Entretanto, a conectividade da vegetação melhorou ao analisamos o meff: de 0,4\%, em 2012 para $16,8 \%$ em 2013. Estes valores apontam que, embora a cobertura arbórea tenha diminuído, houve maior conectividade entre os fragmentos. Em seu trabalho, Doubrawa et al. (2013) [21], utilizando imagens do sensor HRC do projeto sino-brasileiro CBERS 2B, de resolução espacial de 2,7 m, apontam que as árvores inseridas no tecido urbano ocupam 9,96\% do total da área, distribuídas em pequenas concentrações, conforme verificado pelos valores do meff. No entanto, embora concentrados, foi visto que estes fragmentos estão mais conectados. O aumento na conectividade aponta o possível desenvolvimento de indivíduos jovens interpretados pelo meff como novas conexões entre fragmentos já existentes. É desejável que a floresta urbana seja homogênea na cidade, de modo a proporcionar os benefícios da arborização urbana a todos os habitantes.

\section{CONCLUSÃO}

Houve subestimação da cobertura arbórea analisada pelo satélite RapidEye. Entretanto, foi possível observar que houve aumento da conectividade dos fragmentos arbóreos de 2012 para 2013. A promoção da conectividade da cobertura florestal urbana, por meio do manejo e plantio de novos indivíduos, é essencial para que a vegetação se mantenha distribuída homogeneamente. Assim os benefícios das florestas urbanas atingirão um maior número de pessoas.

A imagem do satélite RapidEye classificou corretamente os parques urbanos, mas, quando analisamos a cobertura arbórea presente em vias públicas, houve subestimação em função da resolução espacial. Satélites com sensores de maior resolução, como o WorldView 2 (pixels de 0,5 m de lado), são ideais para análises a nível urbano, porém, seus altos custos de aquisição ainda impedem sua aplicação em uma variedade maior de trabalhos.

A resolução espacial e a qualidade das imagens influenciam diretamente na identificação de classes de uso e ocupação do solo. No caso, foi possível separar somente sete classes devido ao pixel de $5 \mathrm{~m}$ de resolução espacial. A decomposição de mais classes de telhados e a identificação da classe "Piscina", por exemplo, foi prejudicada.

$\mathrm{O}$ algoritmo que melhor identificou e classificou as imagens estudadas foi o ECHO (Extraction and Classification of Homogeneous Objects), seguido pelo Maximum Likelihood e Minimum Euclidean Distance.

\section{REFERÊNCIAS BIBLIOGRÁFICAS}

1. Schupp D. Umweltindikator landschaftszerschneidung: Ein zentrales element zur verknüpfung von wissenschaft und politik. Gaia 2005 Jun: 14(2):101-6.

2. Lang S, Blaschke T. Análise da paisagem com SIG. Tradução de Hermann Kux. São Paulo: Oficina de Textos; 2009. 424 p.

3. Jung M. LecoS. A QGIS plugin for automated landscape ecology analysis. PeerJ 2013 Nov: 1(116):1-6, doi: 10.7287 /peerj.preprints.116v1.

4. Jaeger JAG. Landscape division, splitting index and effective mesh size: New measures of landscape fragmentation. Landsc. ecol. 2000 Feb: 15(2):115-30, DOI: 10.1023/A:1008129329289.

5. Girvetz EH, Thorne JH, Berry AM, Jaeger JAG. Integrating habitat fragmentation analysis into transportation planning using effective mesh size landscape metric. In: Irwin CL, Nelson D, McDermott KP, editors. Center for Transportation and the Environment. Proceedings of the 2007 International Conference on Ecology and Transportation; 2007 May 20-25; Little Rock, USA. Little Rock: ICOET; 2007. p. 281-93.

6. Moser B, Jaeger JAG, Tappeiner U, Tasser E, Eiselt B. Modification of the effective mesh size for measuring landscape fragmentation to solve the boundary problem. Landsc. ecol. 2007 Mar: 22(3):44759, DOI: 10.1007/s10980-006-9023-0. 
7. Girvetz EH, Thorne JH, Berry AM, Jaeger JAG. Integration of landscape fragmentation analysis into regional planning: A statewide multi-scale case study from California, USA. Landsc. urban plan. 2008 Jun: 86(3-4):205-18, doi:10.1016/j.landurbplan.2008.02.007.

8. Jaeger JAG, Bertiller R, Schwick C, Müller K, Steinmeier C, Ewald KC, Ghazoul J. Implementing landscape fragmentation as an indicator in the Swiss Monitoring System of Sustainable Development (MONET). J. environ. manag. 2008 Sept: 88(4):737-51, doi:10.1016/j.jenvman.2007.03.043.

9. Gao J, Li S. Detecting spatially non-stationary and scale-dependent relationships between urban landscape fragmentation and related factors using Geographically Weighted Regression. Appl. geogr. 2011 Jan: 31(1):292-302, doi:10.1016/j.apgeog.2010.06.003.

10. Freitas SR, Alexandrino MM, Pardini R, Metzger JP. A model of road effect using line integrals and a test of the performance of two new road indices using the distribution of small mammals in the Atlantic Forest landscape. Ecol. Model. 2012 Dec: 247:64-70, doi:10.1016/j.ecolmodel.2012.07.033.

11. Marull J, Tello E, Wilcox PT, Coll F, Pons M, Warde P, Valldeperas N, Ollés A. Recovering the landscape history behind Mediterranean edge environment (The Congost Valley, Catalonia, 18542005): The importance of agroforestry systems in biological conservation. Appl. geogr. 2014 Oct: 54:117, doi:10.1016/j.apgeog.2014.06.030.

12. Su S, Yang C, Hu Y, Luo F, Wang Y. Progressive landscape fragmentation in relation to cash crop cultivation. Appl. geogr. 2014 Sept: 53:20-31, doi:10.1016/j.apgeog.2014.06.002.

13. Satellite Imaging Corporation. RapidEye Satellite Sensor (5m). 2015. [acesso em 2015 jun 29]. Disponível em: http://www.satimagingcorp.com/satellite-sensors/other-satellite-sensors/rapideye/.

14. Barros ZX, Tornero MT, Stipp NAF, Cardoso LG, Pollo RA. Estudo da Adequação do Uso do Solo, no Município de Maringá - PR, utilizando-se de geoprocessamento. Eng. Agric. 2004 May/Aug: 24(2):436-44, http://dx.doi.org/10.1590/S0100-69162004000200024.

15. Prefeitura Municipal de Maringá. Plano municipal de conservação e recuperação da Mata Atlântica. Maringá - Paraná. Maringá: Prefeitura do Município de Maringá; 2011. 113 p.

16. Maack R. Geografia física do Estado do Paraná. Curitiba: Max Roesner; 1968. 350 p.

17. Prefeitura Municipal de Maringá. Plano de manejo do horto florestal de Maringá (Horto florestal Dr. Luiz Teixeira Mendes). Maringá: IGPlan; 2013. 221 p.

18. Geo Catálogo. Acesso às imagens de satélite RapidEye do Ministério do Meio Ambiente. 2015. [acesso em 2015 jun 30]. Disponível em: http://geocatalogo.ibama.gov.br/.

19. Landis JR, Koch GG. The measurement of observer agreement for categorical data. Biometrics 1977 Mar: 33(1):159-74, DOI: 10.2307/2529310.

20. Sampaio ACF, Blum CT, Germano PJMMT, De Angelis BLD. Avaliação da cobertura florestal no município de Maringá, Paraná. Revsbau 2012, 7(2):89-101.

21. Doubrawa B, Dalla Corte AP, Sanquetta CR. Using different satellite imagery and classification techniques to assess the contribution of these outside forests in the municipality of Maringá, Brazil. Rev. Ceres 2013 Jul/Aug: 60(4):480-8, http://dx.doi.org/10.1590/S0034-737X2013000400006. 